\title{
OPÇÕES DIDÁTICAS PARA O FOMENTO DA EDUCAÇÃO AMBIENTAL NO ENSINO BÁSICO DE TEMPO INTEGRAL
}

\author{
Paulo Amador Tavares ${ }^{1}$ \\ Norma Ely Santos Beltrão² \\ Lianne Borja Pimenta ${ }^{3}$
}

Resumo: Os desafios da sustentabilidade no Brasil, tem levado a discutir a inserção da educação ambiental em um contexto de crescente interdisciplinaridade nos conteúdos programáticos de ensino básico. Recentemente, ênfase também tem sido dada ao ensino integral. Neste contexto, este artigo busca identificar opções didáticas de práticas de educação ambiental para o ensino básico considerando um cenário de ensino integral. Para isso, realizou-se uma pesquisa bibliográfica com uma abordagem exploratória. Entre os resultados encontrados, destaca-se que há espaço para desenvolvimento de educação ambiental crítica, o que pode ser feito utilizando as várias opções didáticas relatadas neste artigo.

Palavras-chave: Educação Ambiental; Interdisciplinaridade; Ensino Básico; Ensino Integral; Políticas Públicas.

\footnotetext{
1 Universidade do Estado do Pará. E-mail: atavares.paulo@gmail.com

2 Universidade do Estado do Pará. E-mail: normaelybeltrao@gmail.com

3 Universidade do Estado do Pará. E-mail: lianneborja@yahoo.com.br.
}

revista brasileira educação ambiental 


\section{Introdução}

A educação interdisciplinar vem se fortalecendo na construção de conteúdos programáticos em todo o mundo (UNESCO, 2016; GOUGH, 2003; SMITH, 2003). De acordo com Gough (2003), isso acontece por dois fatores, o primeiro é que os organismos internacionais como a Organização das Nações Unidas (ONU) desenvolveram um substancial aporte teórico para o desenvolvimento de técnicas de ensino interdisciplinares aplicáveis para todos os países, e o segundo motivo é que os conteúdos interdisciplinares sempre buscam a abordagem de temas globais, ou seja, temas que envolvam questões e problemas que fazem parte do cotidiano de indivíduos pertencentes a todas as localidades, considerando as suas especificidades.

O estudo de Volpe e Suldo (2014) mostrou que a educação multidisciplinar teve resultados eficientes para estudantes diagnosticados com déficit de atenção e transtornos de hiperatividade. Os autores afirmam que a metodologia interdisciplinar além de permitir uma melhor absorção dos conteúdos pelos estudantes, também permite 0 desenvolvimento do pensamento crítico sobre diversos assuntos relativos ao seu ensino básico.

Relacionada ao estudo interdisciplinar, surge a educação ambiental na década de 1970 com o aumento da preocupação em torno da degradação do meio ambiente (PROFICE, 2016; GOUGH, 2013; GOUGH, 2013; STEVENSON, 2007). Gough (2013) mostra o desenvolvimento do pensamento sobre a educação ambiental no mundo e como essa metodologia de ensino auxilia os alunos na busca de resultados positivos para o meio ambiente que atinjam a todos, mesmo que suas ações sejam feitas localmente.

No Brasil, os autores Layrargues (2002), Pelicioni (2004) e Dias (2015) destacam a evolução da educação interdisciplinar, focada na educação ambiental. Esses autores abordam a temática crítica que o estudo interdisciplinar permite aos alunos e interagem com o modo que a educação ambiental é tratada dentro da sala de aula e o modo que ela deveria ser desenvolvida para alcançar resultados mais eficazes. Percebe-se então a necessidade da inserção de atividades interdisciplinares dentro do universo do ensino básico (WALS et al., 2014; FRADE; MEIRA, 2012; JONES, 2010).

No ensino básico, nota-se a constante tendência de inserção de ensino em período integral (POSSER, ALMEIDA; MOLL, 2016; TITTON; PACHECO, 2015; BRANCO, 2012). Os autores Leite e Ramalho (2015), Carvalho (2015), mostram em seus estudos que o ensino integral se torna eficiente para os alunos quando este período de ensino é agregado à inserção de metodologias que abordem questões gerais e não somente disciplinas específicas e diretas. Por causa disso, acredita-se que o ensino da educação ambiental é um artifício fundamental para o desenvolvimento do ensino integral.

Os autores Wals et al. (2014), em sua análise exploratória sobre a educação ambiental e a educação da ciência no mundo, mostraram que o ensino da educação ambiental no ainda é focado em estudos de casos e que esses estudos costumam ser lineares, porque eles constroem uma relação

Revbea, São Paulo, V. 12, № 4: 25-43, 2017. 
somente com o conhecimento, a sensibilização, a atitude e o comportamento dos cidadãos em relação ao meio ambiente. Os autores destacam que esse método de abordagem é considerado por psicólogos sociais como simplório e muito distante de algo que possa interferir nas ações das pessoas em relação ao ambiente.

Desta forma, Wals et al. (2014) concordam com Layrargues (2002) na defesa de um ensino de educação ambiental que aborde metodologias de ensino críticas, com as quais os indivíduos possam desenvolver o seu pensamento crítico, ético e criativo para avaliar as situações ambientais em que ele está envolvido.

Jones (2010) em seu estudo sobre a interdisciplinaridade no ensino básico, salienta que a inserção da multidisciplinaridade dentro do ambiente escolar requer um trabalho árduo e contínuo de toda a equipe pedagógica. Entretanto, o autor destaca que os resultados desta prática podem trazer para os envolvidos, tanto alunos quanto professores, como o desenvolvimento do pensamento crítico, melhoria na comunicação e relações sociais, criatividade e pedagogia de aula, são positivos para a melhoria da qualidade de ensino e formação de cidadãos honestos.

Pelos motivos abordados, constata-se enfim a necessidade do desenvolvimento de pesquisas que apresentem opções didáticas para o fomento da educação ambiental no ensino básico formal do Brasil. Um desafio encontrado na literatura é o embate entre a educação ambiental tradicional e a crítica. Isto acontece, pois, os estudos desenvolvidos no ensino básico brasileiro costumam abordar questões individuais e não globais, sem que seja desenvolvido um pensamento crítico nos alunos e educadores ambientais envolvidos nos estudos de caso.

Além disso, deve haver uma especial atenção com as metodologias escolhidas pelos coordenadores pedagógicos das instituições de ensino, pois devem adotar a abordagem multidisciplinar da educação ambiental. Nesta abordagem, busca-se desenvolver o conhecimento sobre as questões ambientais de maneira global, de tal modo que possa atender a todas as disciplinas que constituem o plano pedagógico da instituição.

Por isso, esta pesquisa tem como objetivo analisar as opções didáticas de educação ambiental que podem ser inseridas no ensino básico brasileiro dentro de um cenário de ensino integral. $O$ trabalho analisa estudos de caso realizados no Brasil e argumenta como essas interpretações didáticas da educação ambiental podem contribuir e existir dentro de um cenário de ensino integral e interdisciplinar. 


\section{Educação formal no brasil: histórico e recente desenvolvimento}

A educação no Brasil tem passado por constantes mudanças desde o início da década de 1960, principalmente em relação ao que é proposto para ensino médio (MOEHLECKE, 2012; KRAWCZYK, 2009), possível reflexo das mudanças que também ocorreram na política brasileira (FAGNANI, 1997). A relação entre as mudanças políticas e as formas de ensino básico dialoga com os autores Hursh, Henderson e Greenwood (2015), que chamam atenção para o fato de que a educação ambiental está diretamente relacionada aos fatores políticos existentes, e desta forma, o modo de pensamento político predominante no país, poderia alterar a forma de implantação da educação ambiental.

Moreira (2003) argumenta que o currículo brasileiro de educação básica teve grande influência do modelo de ensino americano até o começo da década de 1970. O desenvolvimento de ideias críticas sobre o ensino e a necessidade de se englobar as ideias políticas, econômicas e culturais sobre o Brasil, fez com que a rejeição as experiências internacionais de ensino crescessem. A partir da segunda metade da década de 1970 e durante as décadas de 1980 e 1990, o autor expõe que houve transformações na mentalidade de ensino no Brasil, tornando as questões relacionadas ao país em maior evidência no conteúdo programático das disciplinas.

No ano de 1971, com a pressão do regime militar brasileiro por mudanças no ensino básico, houve a implantação da profissionalização compulsória no ensino médio com a Lei № 5.692/71, fazendo com que não houvesse a necessidade de ampliação do ensino superior. Entretanto, essa medida foi ineficaz e abolida em 1982 como aponta Moehlecke (2011).

A Constituição da República Federativa do Brasil (BRASIL,1988), foi um marco histórico importante para que o sistema de educação no país tornasse um bem de todos os cidadãos. Prova disso são ideias como a "liberdade de aprender, ensinar, pesquisar e divulgar o pensamento, a arte e $o$ saber" (Art. 206, inciso II), o "pluralismo de ideias e concepções pedagógicas, a coexistência de instituições públicas e privadas de ensino" (Art. 206, inciso III), a "progressiva universalização do ensino médio gratuito" (Art. 208, inciso II) e "educação infantil, em creche e pré-escola, às crianças até 5 (cinco) anos de idade" (Art. 208, inciso IV) todas garantidas com a Constituição de 1988.

Essa Constituição também fundamentou o desenvolvimento da Lei de Diretrizes e Bases (LDB), Lei № 9.394 de 20 de dezembro de 1996, e das Diretrizes Curriculares Nacionais para o Ensino Médio (DCNEM) de 1998, que está presente na Resolução da Câmara de Educação Básica (CEB) de 26 de junho de 1998. Ambos dispositivos legais englobam a formação para a continuidade dos estudos, o desenvolvimento da cidadania e do pensamento crítico, assim como a preparação técnica para o trabalho, assegurada a formação geral.

Com o intuito de criar metas para se alcançar os objetivos indicados pela Constituição de 1988 e as posteriores LDB e DCNEM, desenvolveu-se o Revbea, São Paulo, V. 12, № 4: 25-43, 2017. 
Plano Nacional de Educação (PNE), Lei № 10.172 de 9 de janeiro de 2001, com metas a serem alcançadas entre 2001 e 2010. Entretanto, os estudos de Moehlecke (2011) e Aguiar (2010), mostram que a educação brasileira atual ainda se encontra distante do que foi pretendido com a implantação do PNE.

Com a necessidade de manutenção e melhoria dos objetivos e metas definidos para a continuidade de avanços na qualidade e democratização da educação no Brasil (SAVIANI, 2010), foi aprovada a Emenda Constitucional $\mathrm{N}^{\circ}$ 59, de 11 de novembro de 2009, que tornou o PNE obrigatório e decenal, garantindo a manutenção e desenvolvimento do ensino em seus diversos níveis. A obrigatoriedade da existência de do PNE, fez com que em 2014 foi aprovada a Lei № 13.005, de 25 de junho de 2014, o PNE válido de 2014 até 2024.

Outro marco histórico para a educação no Brasil foi a reforma do ensino médio proposta com a Lei № 13.415 , de 16 de fevereiro de 2017 , que prevê a implantação do período integral para todo o ensino médio, aumentando a carga horária de 800 horas para 1.000 horas nos cinco primeiros anos da alteração da Lei e para 1.400 horas nos anos seguintes, sem prazo definido. $O$ ensino integral, como exposto por Posser, Almeida e Moll (2016), busca o desenvolvimento pleno do ser humano baseado na integração e ampliação do tempo, espaço e conteúdo de aprendizagem, associando os conhecimentos adquiridos na escola, na comunidade e no contexto familiar visando à construção de uma educação de tempo integral de qualidade.

\section{Educação ambiental no brasil}

A educação ambiental a nível mundial ganhou força a partir da Conferência das Nações Unidas sobre o Meio Ambiente e o Desenvolvimento, a Rio-92, onde, de acordo com Layrargues e Lima (2014) e Pelicioni (1998), recomendou-se que a educação ambiental deveria reorientar a educação para o desenvolvimento sustentável de forma a compatibilizar os objetivos sociais, os objetivos ambientais e os objetivos econômicos, além de aumentar a conscientização popular, considerar o analfabetismo ambiental e promover treinamento.

$\mathrm{Na}$ educação básica brasileira, têm-se a educação ambiental, prevista na Lei № 6.938 de 31 de agosto de 1981 que dispõe sobre a Política Nacional do Meio Ambiente (PNMA). A PNMA articula que a educação ambiental deve ser disponibilizada "a todos os níveis de ensino, inclusive a educação da comunidade, objetivando capacitá-la para participação ativa na defesa do meio ambiente" (Art. $2^{\circ}$, inciso X).

Com base na PNMA, surge em 1999 a Lei № 9.795, de 27 de abril de 1999, que dispõe sobre a Política Nacional de Educação Ambiental (PNEA), como um processo formal ou não formal para garantir "o desenvolvimento de uma compreensão integrada do meio ambiente em suas múltiplas e complexas relações, envolvendo aspectos ecológicos, psicológicos, legais, políticos, sociais, econômicos, científicos, culturais e éticos" (Art. $5^{\circ}$, inciso I).

revista brasileira educação ambiental 
A educação ambiental também é um artifício fundamental descrito no Marco de Ação do Projeto Educação 2030 da UNESCO (2016), relacionado com as metas globais para o desenvolvimento sustentável até 2030 , que afirma que se deve:

até 2030, garantir que todos os alunos adquiram as habilidades necessárias para promover o desenvolvimento sustentável, inclusive, entre outros, por meio da educação para o desenvolvimento sustentável e estilos de vida sustentáveis, direitos humanos, igualdade de gênero, promoção de uma cultura de paz e não violência, cidadania global e valorização da diversidade cultural e da contribuição da cultura para o desenvolvimento sustentável (UNESCO, 2016).

Layrargues (2002) argumenta que o desenvolvimento da educação ambiental no Brasil ainda encontra o empecilho da força que os métodos de ensino tradicionais possuem dentro das salas de aula. Rodrigues e Andreoli (2016) e Evangelista e Vital (2013) destacam que outra dificuldade para a implantação de técnicas críticas de ensino de educação ambiental no Brasil é que muitos professores ainda encontram dificuldades em inserir a educação ambiental em suas disciplinas e que por vezes os professores não possuem conhecimento necessário para desenvolver a educação ambiental dentro das salas de aula.

\section{A educação ambiental como ferramenta interdisciplinar de agregação no ensino básico}

O PNE brasileiro em associação com o novo regime de ensino médio (BRASIL, 2016), mostra a necessidade de atividades interdisciplinares como fator de agregação do ensino médio de qualidade. Dentre as diversas disciplinas interdisciplinares que podem ser utilizadas no ensino médio, está a educação ambiental.

Pelicioni (2004) e Layrargues (2002) destacam a existência de duas abordagens para educação ambiental. A primeira linha de pensamento é conhecida como a teoria clássica ou convencional, onde as disciplinas são abordadas separadamente, não existindo a correlação de assuntos entre a educação ambiental e as disciplinas e a vida pessoal dos estudantes. Ou seja, nessa abordagem a interdisciplinaridade oferecida pela educação ambiental, não é explorada.

A segunda abordagem relatada para a educação ambiental é a crítica, defendida por diversos autores (GUIMARÃES, 2004; LOUREIRO, 2004; PELICIONI, 2004) como fundamental para o desenvolvimento de seres humanos atuantes dentro das necessidades da sociedade. A teoria crítica propõe a inserção dos estudantes em pensamentos que relacionem o ambiente com o contexto socioeconômico, político e cultural que o influencia. Tal pensamento torna o estudo da educação ambiental de fato interdisciplinar Revbea, São Paulo, V. 12, № 4: 25-43, 2017. 
capaz de desenvolver o pensamento crítico e transformador sobre os riscos ambientais (ROSA et al., 2015).

Freire (1974) em seu trabalho sobre a "Pedagogia do Oprimido", o qual é objeto de estudo de diversos autores (BRIGHENTE; MESQUIDA, 2016; LINHARES, 2008; PEROSA ; MESQUIDA, 2008; PELICIONI, 2004), descreve a educação tradicional como uma educação bancária, uma vez que este tipo de educação tem como objetivo depositar no aluno conhecimentos, informações, dados e fatos que são acumulados como um produto. Desta forma, o conhecimento gerado pelos estudantes tem como característica apenas a reprodução das situações que são apresentadas dentro das salas de aula, sem a preocupação de tornar aqueles indivíduos em seres pensantes e críticos.

Nota-se então, a necessidade da dissociação da educação convencional para a dita sustentável, como expresso por Layrargues (2002) e Layrargues e Lima (2014), sem que a educação ambiental seja vista como uma disciplina singular e a única encarregada de apresentar os valores ambientais contra um processo inteiro de educação convencional que não instiga o pensamento crítico em relação ao meio ambiente. Os autores argumentam que a educação ambiental só pode existir no plural, pois ela deve agregar conhecimentos de diversas áreas para instigar o conhecimento crítico dentro da educação básica.

O conhecimento e prática da educação ambiental de maneira eficiente servem para a melhoria não só na qualidade de vida e no bem-estar da sociedade, mas também para contribuir para um ambiente sustentável, aumentando a preocupação dos indivíduos de amanhã com as questões ambientais (OLIVEIRA, 2016; SIMSEKLI, 2015; SOUZA et al., 2013). Oliveira (2016) destaca que a educação ambiental deve ser popular, participativa, crítica, transformadora e emancipatória, de tal forma que possa influenciar na elaboração de políticas públicas socioambientais no Brasil.

Se para Moran (2013) e Pelicioni (2004) o educador não é aquele que educa, mas sim aquele que cria condições para que as ideias e os conhecimentos sejam incorporados pelo educando, fazendo com que a educação sempre provoque mudanças, mesmo que inconscientes, vindo de dentro para fora, então para Rosa et al. (2015) a educação ambiental é:

compreendida como uma estratégia de reflexão para a sociedade ou grupo pelo qual é desenvolvida no intuito de novamente estabelecer valores e criar uma nova identidade ao indivíduo, considerando que este só poderá ser formado de modo a demonstrar o amadurecimento ambiental com base em um projeto que o insira como formador de opinião e não apenas como cumpridor de ordens ou regras. Sobretudo, the permita fazer parte do problema, o que lhe dá possibilidade de se enxergar como uma das chaves para a solução (ROSA et al., 2015, p. 212). 
Assim, surge a necessidade de se agregar o conhecimento ambiental às necessidades educacionais de estudo do ensino básico (PROFICE, 2016; OLIVEIRA, 2016; MESQUITA et al., 2014; TORNQUIST et al., 2013; VEIGA et al., 2012). No entender de Bernardes e Prietro (2010), o papel da Educação Ambiental, sem dúvida perpassa todas as áreas do conhecimento e exige reflexões acerca da problemática ambiental e também sobre a educação no Brasil, em que os conhecimentos pouco dialogam uns com os outros. De acordo com Xavier et al. (2011), a educação ambiental é o caminho para o desenvolvimento processual da consciência ecológica na formação do educando, pois contribui para a concepção de uma sociedade sustentável.

Entretanto, a educação ambiental enfrenta desafios para a sua correta implantação dentro das salas de aula do ensino básico brasileiro. Evangelista e Vital (2013) destacam os desafios encontrados pelos professores do ensino básico em desenvolver atividades de educação ambiental dentro das salas de aula na rede pública estadual de Sumé, Paraíba, Brasil. Este estudo apontou que nas instituições de ensino que fizeram parte da pesquisa, existe a vontade dos professores e pedagogos da instituição em realizar ações de educação ambiental com os alunos, entretanto, os professores não possuem afinidade com a maior parte das temáticas relacionadas à educação ambiental.

Nesse mesmo sentido, o estudo de caso realizado por Pereira e Gibbon (2014) destacou que existe resistência dos educadores da área de estudo em aceitar o tema de educação ambiental como transversal e inerente a todas as disciplinas. $O$ estudo mostrou que há o desafio de envolver o corpo docente dentro das atividades e de estimular os próprios professores a aprenderem sobre o assunto para instigarem os discentes.

Essa abordagem de desafios encontrados pela educação ambiental no Brasil também é reforçada pelo estudo de Rodrigues e Andreoli (2016), no qual a pesquisa dentro de salas de aula comprovou que os professores têm dificuldades em abordar temas relacionados à educação ambiental. Por causa da falta de afinidade que os professores da instituição de ensino estudada tinham em relação aos temas relacionados à educação ambiental, notou-se que as atividades propostas pelos docentes não instigavam os discentes a serem protagonistas no desenvolvimento de soluções para problemas ambientais. Os alunos também não eram ensinados e estimulados a desenvolver conhecimentos sobre os problemas ambientais locais.

A educação ambiental no Brasil também encontra desafios como os expostos por Otero e Neiman (2015), onde foi argumentado que a educação ambiental possui um elevado nível de complexidade e abrangência de temas. O autor destaca que há a necessidade de expor ações que possam formar cidadãos conscientes e que possam expor as contradições da sociedade e que possam promover mudanças socioambientais. Por estes fatos, nem todos os profissionais da educação conseguem abordar a vastidão de temas da educação ambiental e acabam focando em áreas específicas e planos de ação restritos somente a uma área de atuação. 
Os relatos de Evangelista e Vital (2013), Pereira e Gibbon (2014), Rodrigues e Andreoli (2016) e Otero e Neiman (2015), destacam que a educação ambiental possui diversos desafios que devem ser ultrapassados para que a forma de ensino se torne eficaz. Há concordância entre esses autores que a disciplina de educação ambiental deve possuir abordagem interdisciplinar e que há a necessidade de capacitação para que os professores se tornem competentes para ministrar aulas e desenvolver ações juntamente com os alunos.

\section{Procedimentos metodológicos}

O delineamento do presente trabalho consiste de pesquisa descritiva que, segundo Gil (2008), tem como objetivo a descrição das características de determinado fenômeno, estabelecendo a relação entre as variáveis. Com a pesquisa descritiva é possível classificar, explicar e interpretar os fatos que ocorrem a partir dos objetivos propostos no estudo (PRODANOV; FREITAS, 2013). Utilizou-se como procedimento a pesquisa bibliográfica através de uma revisão de literatura que analisou estudos relevantes que tratam das opções didáticas de educação ambiental para um cenário de ensino médio integral.

A coleta de dados para a revisão de literatura foi realizada através de indexadores em bases de registro de bibliografias eletrônicas, do Directory of Open Access Journals, o Google Acadêmico e os Periódicos da CAPES. Nestes indexadores, foram selecionados artigos da Revista Brasileira de Educação Ambiental que apresentassem estudos de caso de educação ambiental e os resultados desses estudos de caso, destacando-se aqueles que apresentassem maior transversalidade no tema de educação ambiental, de tal forma que fosse elaborado um estado da arte sobre a abordagem do tema nesta revista (CORRÊA; VASCONCELOS; SOUZA, 2013; SAMPIERI, COLLADO e BAPTISTA LUCIO, 2013).

Realizou-se a discussão com outros autores específicos da área de educação ambiental através da análise dos objetivos, métodos e resultados encontrados nos artigos selecionados. A discussão teve a intenção de identificar a aplicação das metodologias de educação ambiental existente com o cenário de ensino integral e de educação ambiental crítica no Brasil (POSSER; ALMEIDA; MOLL, 2016; COSTEL, 2015; BEGNINI; CASAGRANDE, 2014; LAYRARGUES, 2002).

\section{Abordagens didáticas de educação ambiental para o ensino básico de período integral brasileiro}

O estudo de Costel (2015) apresenta metodologias didáticas para a integração da educação ambiental ao contexto do ensino básico. $O$ autor acredita que deve existir uma mistura entre a teoria e a prática dentro da educação ambiental, e que esta mistura deve ser feita considerando os contextos sociais em que o ensino desta disciplina estará inserido. Desta forma, o ensino da educação ambiental dependerá da necessidade da 
sociedade e no quanto este ensino poderá trazer de retorno social, econômico e ambiental para a sociedade.

A revisão da literatura sobre a educação ambiental no Brasil mostra que diversas ações estão sendo tomada nos diversos estados da federação. $O$ quadro 1 apresenta métodos didáticos de educação ambiental em cada região do Brasil e como eles são abordados dentro das escolas.

Quadro 1 - Práticas de educação ambiental em diversas localidades do Brasil.

\begin{tabular}{|c|c|c|c|}
\hline Autor & Estado & Objetivos/Metodologia & Resultados \\
\hline $\begin{array}{l}\text { Paulino et } \\
\text { al. (2017) }\end{array}$ & $\begin{array}{l}\text { Minas } \\
\text { Gerais }\end{array}$ & 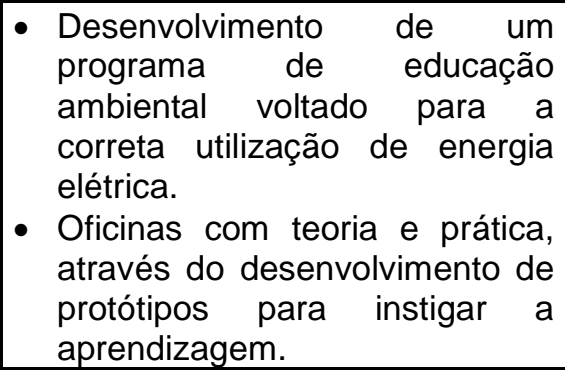 & $\begin{array}{l}\text { - Projeto realizado em } 5 \text { meses, o } \\
\text { que facilitou a plena } \\
\text { compreensão dos conteúdos } \\
\text { ministrados. } \\
\text { - A participação do corpo docente } \\
\text { da instituição facilitou o processo } \\
\text { de aprendizagem. }\end{array}$ \\
\hline $\begin{array}{c}\text { Menezes } \\
\text { et al. } \\
\text { (2017) }\end{array}$ & Bahia & $\begin{array}{l}\text { - Elaborou-se um jogo didático } \\
\text { como ferramenta para a } \\
\text { educação ambiental. } \\
\text { - Foi feita uma intervenção } \\
\text { ambiental por meio de uma } \\
\text { palestra e aplicação do jogo } \\
\text { didático. } \\
\text { - O questionário para } \\
\text { investigação da percepção } \\
\text { ambiental dos participantes foi } \\
\text { aplicado antes da palestra e } \\
\text { outro após a palestra. }\end{array}$ & $\begin{array}{l}\text { - Os alunos passaram a se } \\
\text { preocupar com as questões } \\
\text { ambientais na área de estudo. } \\
\text { - O jogo "Reconquista da Mata } \\
\text { Ciliar" possuiu um valor } \\
\text { significativo, enquanto objeto } \\
\text { educacional e pedagógico. } \\
\text { - A metodologia utilizada pode ser } \\
\text { utilizada para a estruturação de } \\
\text { projetos políticos pedagógicos } \\
\text { relacionados ao tema de } \\
\text { Educação Ambiental. }\end{array}$ \\
\hline $\begin{array}{l}\text { Machado, } \\
\text { Vestena e } \\
\text { Folmer } \\
(2016)\end{array}$ & $\begin{array}{c}\text { Rio } \\
\text { Grande } \\
\text { do Sul }\end{array}$ & $\begin{array}{l}\text { - Estudo realizado dentro das } \\
\text { salas de aula. } \\
\text { - Conscientização sobre a coleta } \\
\text { e uso da água da chuva. }\end{array}$ & $\begin{array}{l}\text { - O estudo promoveu a } \\
\text { conscientização sobre o uso } \\
\text { racional de água. } \\
\text { - Ensino de metodologia para a } \\
\text { captação de água da chuva. }\end{array}$ \\
\hline $\begin{array}{l}\text { Santos, } \\
\text { Schimitt e } \\
\text { Rosa } \\
(2016)\end{array}$ & $\begin{array}{c}\text { Rio } \\
\text { Grande } \\
\text { do Sul }\end{array}$ & $\begin{array}{l}\text { - Os participantes são instigados } \\
\text { a diminuir a produção de } \\
\text { resíduos sólidos. } \\
\text { - Transformação dos resíduos } \\
\text { para não ser enviado para } \\
\text { aterros sanitários. }\end{array}$ & $\begin{array}{l}\text { - Referência no Rio Grande do Sul. } \\
\text { - Adesão de diversos setores da } \\
\text { escola. } \\
\text { - A sensibilização permanente é } \\
\text { instigada. }\end{array}$ \\
\hline $\begin{array}{c}\text { Fonseca } \\
(2016)\end{array}$ & $\begin{array}{l}\text { Rio de } \\
\text { Janeiro }\end{array}$ & 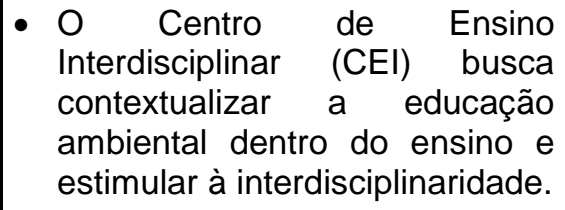 & $\begin{array}{l}\text { - Formação de cidadãos } \\
\text { capacitados para o mercado de } \\
\text { trabalho. } \\
\text { - Abordagens sobre problemas } \\
\text { ambientais comuns a todos. }\end{array}$ \\
\hline
\end{tabular}

Continua...

Revbea, São Paulo, V. 12, № 4: 25-43, 2017. 
...continuação.

\begin{tabular}{|c|c|c|c|}
\hline Autor & Estado & Objetivos/Metodologia & Resultados \\
\hline $\begin{array}{c}\text { Cerejeira e } \\
\text { Guerreiro } \\
(2016)\end{array}$ & $\begin{array}{c}\text { Rio } \\
\text { Grande } \\
\text { do } \\
\text { Norte }\end{array}$ & $\begin{array}{l}\text { - Projeto Horta Pedagógica. } \\
\text { - Palestras, minicursos e prática } \\
\text { de montagem da horta foram } \\
\text { utilizadas como ferramentas de } \\
\text { ensino. }\end{array}$ & $\begin{array}{l}\text { - Bom aproveitamento dos } \\
\text { participantes. } \\
\text { - Os alunos demonstraram } \\
\text { grande interesse pelo estudo, } \\
\text { tanto nas disciplinas teóricas } \\
\text { quanto nas aulas práticas } \\
\text { relacionadas à montagem das } \\
\text { hortas pedagógicas. }\end{array}$ \\
\hline $\begin{array}{l}\text { Magalhães } \\
(2016)\end{array}$ & Pará & $\begin{array}{l}\text { - Utilização de ferramentas de } \\
\text { geoprocessamento para a } \\
\text { conscientização dos alunos } \\
\text { sobre questôes relacionadas aos } \\
\text { efeitos da atividade humana na } \\
\text { região. } \\
\text { - Utilização de palestras e oficinas, } \\
\text { jogos de memória e aulas } \\
\text { práticas com o auxílio do } \\
\text { software livre QGIS. }\end{array}$ & $\begin{array}{l}\text { - O uso de jogos de } \\
\text { geoprocessamento se mostrou } \\
\text { adequado para o ensino de } \\
\text { geotecnologias aplicado aos } \\
\text { estudos ambientais. } \\
\text { - Metodologia de baixo custo } \\
\text { para as instituições e com } \\
\text { elevado nível de aceitação } \\
\text { entre os professores e os } \\
\text { alunos. }\end{array}$ \\
\hline $\begin{array}{c}\text { Souza et al. } \\
(2013)\end{array}$ & Bahia & $\begin{array}{l}\text { - Projeto de manejo adequado dos } \\
\text { resíduos sólidos gerados dentro } \\
\text { de uma unidade de ensino } \\
\text { básico. } \\
\text { - Apresentação do tema com } \\
\text { vídeos e imagens, palestras, } \\
\text { atividades práticas e oficinas. }\end{array}$ & $\begin{array}{l}\text { - Professores sem familiaridade } \\
\text { com a Educação Ambiental. } \\
\text { - Os participantes demonstraram } \\
\text { preocupação com as questões } \\
\text { ambientais após o } \\
\text { desenvolvimento da pesquisa. }\end{array}$ \\
\hline $\begin{array}{l}\text { Oliveira e } \\
\text { Oliveira } \\
\text { (2012) }\end{array}$ & $\begin{array}{l}\text { Distrito } \\
\text { Federal }\end{array}$ & $\begin{array}{l}\text { - A pesquisa mostrou que o corpo } \\
\text { docente da instituição foi } \\
\text { instigado pela coordenação } \\
\text { pedagógica a desenvolver } \\
\text { debates dobre questões } \\
\text { ambientais dentro das salas de } \\
\text { aula. } \\
\text { - A instituição já realizou } \\
\text { atividades como: coleta de } \\
\text { resíduos de vidro para } \\
\text { acondicionamento de leite } \\
\text { materno, educação para uso } \\
\text { racional de água e de energia } \\
\text { elétrica. }\end{array}$ & $\begin{array}{llr}\text { - A Fundação } & \text { Bradesco, } \\
\text { Unidade Ceilândia - DF, busca } \\
\text { desenvolver o pensamento } \\
\text { crítico sobre r questões } \\
\text { ambientais } \quad \text { e r sua } \\
\text { multidisciplinaridade. } \\
\text { - A instituição busca adequar as } \\
\text { suas políticas pedagógicas de } \\
\text { ensino às questões ambientais. }\end{array}$ \\
\hline $\begin{array}{c}\text { Tornquist et } \\
\text { al. (2012) }\end{array}$ & $\begin{array}{c}\text { Rio } \\
\text { Grande } \\
\text { do Sul }\end{array}$ & $\begin{array}{l}\text { - Palestras e oficinas práticas } \\
\text { foram utilizadas como método de } \\
\text { ensino. } \\
\text { - Desenvolveu-se um seminário } \\
\text { apresentado pelos alunos e foi } \\
\text { feita a elaboração de um folder } \\
\text { de conscientização sobre o } \\
\text { tema. }\end{array}$ & $\begin{array}{l}\text { - O projeto obteve uma avaliação } \\
\text { positiva dos alunos e dos } \\
\text { professores envolvidos. } \\
\text { - Foram realizadas atividades de } \\
\text { ensino interdisciplinares que } \\
\text { instigaram os alunos nos temas } \\
\text { estudados. } \\
\text { - Os autores destacam a } \\
\text { necessidade da melhora } \\
\text { contínua da educação } \\
\text { ambiental. }\end{array}$ \\
\hline
\end{tabular}

Fonte: Autoria própria, 2017. 
As práticas descritas no quadro 1 relatam a realidade da educação ambiental no Brasil. Percebe-se que as iniciativas não costumam abordar a educação ambiental crítica, que é descrita por Layrargues (2002) e Layrargues e Lima (2014), mas abordam linguagens que tratam a educação ambiental como uma disciplina de sala de aula, como um projeto e com um foco único.

Dentre as experiências práticas relatadas, torna-se importante dar destaque a iniciativas como à descrita por Oliveira e Oliveira (2012). Nota-se que na experiência retratada pelos autores, a Fundação Bradesco, Unidade Ceilândia - DF, a instituição de ensino busca envolver os pensamentos sobre a educação ambiental em todas as disciplinas ministradas nas várias turmas que estão incluídas no ensino básico desta instituição. Desta forma, torna-se possível a aplicação de uma educação ambiental crítica dentro do ensino básico.

É importante ressaltar que as experiências que foram retratadas no quadro 1 abordam diferentes temáticas da educação ambiental. Percebe-se que os autores puderam encontrar resultados positivos em todas as metodologias aplicadas. Nota-se que os resultados costumam ser mais efetivos para a educação ambiental clássica quando ela é acompanhada de experiências práticas como as relatadas por Paulino et al. (2017), onde os autores puderam enfatizar a importância da diminuição do consumo de energia elétrica através da elaboração de palestras com a agregação de oficinas para a criação de protótipos.

Metodologia semelhante foi utilizada por Cerejeira e Guerreiro (2016) onde os ministrantes propuseram a criação de uma horta dentro de área da instituição de ensino. Os autores conseguiram com a aplicação prática do conhecimento ambiental, formar alunos de educação básica com consciência ambiental e que sabem reconhecer a importância de áreas verdes dentro das regiões urbanas.

Magalhães (2016) apresenta uma abordagem diferente em seu estudo de educação ambiental.O autor busca a utilização de ferramentas computacionais de geoprocessamento para instigar os estudantes a compreender os problemas ambientais existentes dentro do município de Santarém. A utilização de técnicas de geoprocessamento tem vantagem sobre as demais técnicas de ensino de educação ambiental, porque pode agregar a experiência prática com a teórica, sem que haja a necessidade de que os discentes tenham que deixar as salas de aula.

As didáticas descritas, apesar de terem encontrado resultados positivos, necessitam evoluir para didáticas críticas como as propostas e descritas por Costel (2015) e Layrargues (2002). A educação ambiental sempre deve objetivar a interdisciplinaridade de disciplinas (LAYRARGUES, 2002). A agregação dos diversos projetos de ensino de educação ambiental abordados pode formar uma importante estratégia político pedagógico interdisciplinar para o ensino básico brasileiro. 
A educação integral no Brasil, que é proposta na Lei № 13.415 de 2017, poderá ser um significante passo para a melhor disseminação da educação integral crítica nas instituições de ensino brasileiras. Os autores Begnini e Casagrande (2014) e Posser, Almeida e Moll (2016) destacam que a educação em período integral é importante para o desenvolvimento global do aluno. Tem-se a educação integral como instrumento para o alcance da interdisciplinaridade de todas as disciplinas, contribuindo para a formação de cidadãos críticos que saibam argumentar e defender os seus pontos de vista. Por causa destes fatores, acredita-se que a obrigatoriedade da educação integral no ensino básico brasileiro será um importante artifício para a promoção da educação ambiental crítica.

Como foi proposto por Costel (2015), é importante que as estratégias de educação ambiental sejam voltadas para as necessidades locais e agregadas a todo o ensino básico, também preconizado por Layrargues e Lima (2014) e Pelicioni (2004). Desta forma, as experiências didáticas relatadas poderão ser estendidas a programas de ensino básico, desde que essas ações tenham a capacidade teórica e prática de atender a demanda local por instruções sobre os temas ambientais específicos da região onde a instituição de ensino estiver localizada. Desta forma, espera-se que a sinergia descrita por Wals (2014) entre a educação ambiental e a ciência cidadã agregada com as tecnologias de informação e comunicação possa enfim ser alcançadas.

\section{Considerações finais}

Ainda que descrita por uma política nacional brasileira e que sejam relatadas experiências individuais com resultados positivos sobre a conscientização ambiental em instituições de ensino básico, é possível notar que a educação ambiental ainda precisa ser potencializada dentro das salas de aula, principalmente ao que se refere à educação ambiental crítica, que tem por fundamento o desenvolvimento de pessoas capazes de pensar e discutir sobre os assuntos relacionados ao meio ambiente.

Com a mudança da carga horária do ensino básico para o período integral, compreende-se que ainda há espaço para as disciplinas explorarem novas áreas instigando a multidisciplinaridade dos alunos. Com isso, cresce o potencial de utilização da educação ambiental, nas suas múltiplas estratégias para a agregação dos conhecimentos interdisciplinares, pois quando trabalhadas em forma de projeto, poderá receber os conhecimentos de cada disciplina, contribuindo para o alcance dos objetivos didáticos e pedagógicos.

Notou-se que os estudos sobre educação ambiental desenvolvidos no Brasil costumam estar relacionados ao método clássico de educação ambiental. Poucas ainda são as iniciativas que tentam agregar a educação ambiental a todo o sistema de ensino da educação básica, para que exista a educação ambiental crítica.

Apesar da forte presença da educação ambiental tradicional nas experiências observadas neste artigo, entende-se que as abordagens Revbea, São Paulo, V. 12, № 4: 25-43, 2017.

revista brasileira educação ambiental 
individuais de educação ambiental relatadas, podem ser reunidas para o desenvolvimento de políticas pedagógicas para o ensino básico brasileiro.

Por fim, acrescenta-se que a iniciativa individual dos gestores de instituições de ensino básico será fundamental para a transformação da educação ambiental no Brasil. Instituições de ensino que transformam o seu método educativo para métodos interdisciplinares se tornam exemplos e objetos de estudos para as demais instituições de uma mesma região. Junto a isto, a obrigatoriedade proposta pela legislação vigente e a correta cobrança pelos órgãos públicos competentes, serão instrumentos fundamentais para que ocorra a implantação de um sistema de ensino multidisciplinar mais eficaz e que possa atender a todos os estudantes da educação básica de maneira igualitária.

\section{Referências}

AGUIAR, M.A.S. Avaliação do Plano Nacional de Educação 2001-2009: Questões para Reflexão. Educação \& Sociedade. Campinas, v. 31, n. 112, p. 707-727, 2010.

BEGNINI, S.; CASAGRANDE, A. Educação integral em tempo integral: O planejamento como ferramenta na gestão. Revista Eletrônica em Gestão, Educação e Tecnologia Ambiental. Santa Maria, v. 18, n. 4, p. 1430-1442, 2014.

BERNARDES, M.B.J.; PRIETO, E. C. Educação Ambiental: Disciplina Versus Tema Transversal. Revista Eletrônica do Mestrado em Educação Ambiental. Rio Grande, v. 24, 2010.

BRANCO, V. Desafios para a Implantação da Educação Integral: Análise das Experiências Desenvolvidas na Região Sul do Brasil. Educar em Revista. Curitiba, n. 45, p. 111-123, 2012.

BRASIL. Lei № 5.692/71, de 11 de agosto de 1971. Fixa Diretrizes e Bases para o ensino de $1^{\circ}$ e $2^{\circ}$ graus, e dá outras providências. Brasília - DF, 1971.

BRASIL. Lei № 6.938, de 31 de agosto de 1981. Dispõe sobre a Política Nacional do Meio Ambiente, seus fins e mecanismos de formulação e aplicação, e dá outras providências. Brasília - DF, 1981.

BRASIL. Constituição da República Federativa do Brasil. Brasília, 1988.

BRASIL. Lei № 9.394, de 20 de dezembro de 1996. Lei de Diretrizes e Bases da educação Brasileira (LDB). Brasília-DF, 1996.

BRASIL. Lei № 9.795, de 27 de abril de 1999. Dispõe sobre a educação ambiental, institui a Política Nacional de Educação Ambiental e dá outras providências. Brasília - DF, 1999.

BRASIL. Lei №. 10.172, de 9 de janeiro de 2001. Estabelece o Plano Nacional de Educação. Diário Oficial da União, Brasília - DF, 2001. 
BRASIL. Constituição (1988). Emenda Constitucional №. 59, de 11 de novembro de 2009. [...] dá nova redação aos incisos I e VII do art. 208, de forma a prever a obrigatoriedade do ensino de quatro a dezessete anos e ampliar a abrangência dos programas suplementares para todas as etapas da educação básica [...]. Brasília - DF, 2009.

BRASIL. Lei № 13.005, de 25 de junho de 2014. Aprova o Plano Nacional de Educação - PNE e dá outras providências. Brasília - DF, 2014.

BRASIL. Lei № 13.415, de 16 de fevereiro de 2017. [...] institui a Política de Fomento à Implementação de Escolas de Ensino Médio em Tempo Integral. Brasília - DF, 2017.

BRIGHENTE, M.F.; MESQUIDA, P. Paulo Freire: da denúncia da educação bancária ao anúncio de uma pedagogia libertadora. Pró-posições. v. 27, n. 1, p. 155-177, 2016.

CÂMARA DE EDUCAÇÃO BÁSICA (CEB). Resolução CEB № 3, de 26 de junho de 1998. Institui as Diretrizes Curriculares Nacionais para o Ensino Médio. Diário Oficial da República Federativa do Brasil. Brasília - DF, 1998.

CARVALHO, L.D. Crianças e Infância na Educação (em Tempo) Integral. Educação em Revista. Belo Horizonte, v. 31, n. 04, p. 23-43, 2015.

CEREJEIRA, J.L.T.; GUERREIRO, T.G.V. Horta pedagógica: Instrumento para disseminação da educação ambiental na clínica pedagógica professor Heitor Carrilho em Natal (RN). Revista Brasileira de Educação Ambiental. São Paulo, v. 10, n. 3, p. 164-176, 2015.

CORRÊA, E.J.; VASCONCELOS, M.; SOUZA, M.S.L. Iniciação à Metodologia: Textos Científicos. Belo Horizonte: NESCON UFMG, 2013.

EVANGELISTA, M.A.A.; VITAL, A.F.M. Visão dos professores da rede pública estadual de Sumé (PB) sobre as dificuldades na condução de ações de educação ambiental. Revista Brasileira de Educação Ambiental. Rio Grande, v. 8, n. 2, p.150-163, 2013.

DIAS, G.F. Atividades Interdisciplinares de Educação Ambiental. $2^{\underline{a}}$ ed. Global Editora e Distribuidora Ltda., 2015.

FAGNANI, E. Política social e pactos conservadores no Brasil: 1964/92. Economia e Sociedade. Campinas, v. 8, p. 183-238, 1997.

FRADE, C.; MEIRA, L. Interdisciplinaridade na Escola: Subsídios para uma zona de desenvolvimento proximal como espaço simbólico. Educação em Revista. Belo Horizonte, v. 28, n. 01, p. 371-394, 2012.

FREIRE, P. Pedagogia do oprimido. $1^{\text {a }}$ ed. Rio de Janeiro: Paz e Terra, 1974.

FONSECA, S.M. A educação ambiental como disciplina. Revista Brasileira de Educação Ambiental. São Paulo, v. 11, n. 1, p. 305-314, 2016.

GIL, A.C. Como elaborar projetos de pesquisa. $4^{\underline{a}}$ ed. São Paulo: Atlas, 2008. 
GOUGH, A. The Emergence of environmental Education Research: A "History" of the Field. In: STEVENSON, R. B.; BRODY, M.; DILLON, J.; WALS, A. E. J. (Ed.). International Handbook on Research in Environmental Education. New York: Routledge, p. 13-22, 2013.

GOUGH, N. Thinking Globally in Environmental Education: A Critical History. In: STEVENSON, R.B.; BRODY, M.; DILLON, J.; WALS, A.E.J. (Ed.). International Handbook on Research in Environmental Education. New York: Routledge, p. 33-44, 2013.

GOUGH, N. Thinking Globally in Environmental Education: Implication for Internationalizing Curriculum Inquiry. In: PINAR, W. F. (Ed.). International Handbook of Curriculum Research. London: LEA Publishers, p. 53-72, 2003.

GUIMARÃES, M. Educação Ambiental Crítica. In: LAYRARGUES, P.P. (Coord.). Identidades da Educação Ambiental Brasileira. Brasília: Ministério do Meio Ambiente, p. 25-34, 2004.

HURSH, D.; HENDERSON, J.; GREENWOOD, D. Environmental Education in a Neoliberal Climate. Environmental Education Research. v. 21, n. 3, p. 299318, 2015.

JONES, C. Interdisciplinary Approach-Advantages, Disadvantages, and the Future Benefits of Interdisciplinary Studies. Essai. v. 7, n. 1, p. 76-81, 2010.

LAYRARGUES, P.P. A crise ambiental e suas implicações na educação. In: QUINTAS, J. S. (Org.). Pensando e praticando a educação ambiental na gestão do meio ambiente. 2ª edição. Brasília: IBAMA, p. 159-196, 2002.

LAYRARGUES, P.P.; LIMA, G.F.C. As Macrotendências Político-Pedagógicas da Educação Ambiental Brasileira. Ambiente \& Sociedade. v. XVII, n. 1, p. 2340, 2014.

LEITE, L.H.A.; RAMALHO, B. Jovens-adolescentes Egressos de uma Educação Integral: A Construção de Atitudes e Valores. Educação em Revista. Belo Horizonte, v. 31, n. 04, p. 63-80, 2015.

LINHARES, L.L. Paulo Freire: Por uma Educação Libertadora e Humanista. In: VII CONGRESSO NACIONAL DE EDUCAÇÂO, EDUCERE, 2008, Curitiba. Anais... Curitiba: PUCPR, p. 10142-10154, 2008.

LOUREIRO, C.F.C. Educação Ambiental Transformadora. In: LAYRARGUES, P.P. (Coord.). Identidades da Educação Ambiental Brasileira. Brasília: Ministério do Meio Ambiente, p. 65-84, 2004.

KRAWCZYK, N. Reflexão sobre alguns desafios do ensino médio no Brasil hoje. Cadernos de Pesquisa. V. 41, n. 144, p. 752-769, 2011.

MACHADO, G.E.; VESTENA, N.P.; FOLMER, I. (Re) uso da água da chuva: Experiência no colégio politécnico de Santa Maria (RS). Revista Brasileira de Educação Ambiental. Rio Grande, v. 11, n, 5, p. 10-18, 2016. 
MAGALHÃES, T.L. Jogos de geotecnologia para o ensino de estudos ambientais no ambiente escolar: Experiência de Santarém (PA). Revista Brasileira de Educação Ambiental. São Paulo, v. 11, n. 2, p. 313-323, 2016.

MENEZES, I.S.; FREITAS, S.H.S.; CARA, P.A.A.; COUTO-SANTOS, A.P.L. Jogo didático como ferramenta para educação ambiental no município de Itapetinga (BA). Revista Brasileira de Educação Ambiental. São Paulo, v. 11, n. 5, p. 19-29, 2017.

MESQUITA, R F.; CARVALHO, M.L.; SOUSA, L.R.M.; LIMA, F.F.; SILVA, G.O.; FERREIRA, A.K.A. Revista Interdisciplinar. V. 7, n. 2, p. 165-172, 2014.

MOEHLECKE, S. O ensino médio e as novas diretrizes curriculares nacionais: entre recorrência e novas inquietações. Revista Brasileira de Educação. v. 17, n. 49, 2012.

MORAN, J.M.; MASETTO, M.; BEHRENS, M. Novas tecnologias e mediação pedagógica. 21를. Ed. Campinas: Papirus, 2013.

MOREIRA, A.F.B. The Curriculum Field in Brazil: Emergence and Consolidation. In: PINAR, W.F. (Ed.). International Handbook of Curriculum Research. London: LEA Publishers, p. 171-184, 2003.

OLIVEIRA, F.A.G. A Educação Ambiental como Meio para a Sustentabilidade. Revista Brasileira de Educação Ambiental. São Paulo, v. 11, n. 5, p. 39-55, 2016.

OLIVEIRA, M.E.; OLIVEIRA, A.M. Educação ambiental e construção de valores: As práticas pedagógicas aplicadas na Fundação Bradesco - Unidade Ceilândia/DF. Revista Brasileira de Educação Ambiental. Rio Grande, v. 7, p. 68-79, 2012.

OTERO, P.B.G.; NEIMAN, Z. Avanços e desafios da educação ambiental brasileira entre a Rio 92 e a Rio +20 . Revista Brasileira de Educação Ambiental. São Paulo, v. 10, n. 1, p. 20-41, 2015.

PAULINO, T.F.; PINTO, M.S.; COSTA, G.V.; BAMBIRRA, M.B.; PAULINO, E.S. Oficinas educacionais: Atividade de extensão como método para a melhor utilização da energia para a melhor utilização da energia para estudantes do ensino fundamental. Revista Brasileira de Educação Ambiental. São Paulo, v. 11, n. 5, p. 139-151, 2017.

PELICIONI, M.C.F. Educação ambiental, qualidade de vida e sustentabilidade. Saúde e Sociedade. v. 7, n. 2, 1998.

PELICIONI, M.C.F. Fundamentos de educação ambiental. In: PHILLIPI, A.; ROMÉRO, M.A.; BRUNA, G.C. Curso de gestão ambiental. Barueri, SP: Manole, p. 459-483, 2004.

PEREIRA, V.A.; GIBBON, C.A. A educação ambiental no ensino: Investigando as abordagens, percepções e desafios na realidade de uma escola pública em Rio Grande (RS). Revista Brasileira de Educação Ambiental. São Paulo, v. 9, n. 2, p. 376-394, 2014.

revista brasileira educação ambiental 
PEROZA, J.; MESQUIDA, P. A Utopia como Condição Antropológica para uma Educação Libertadora em Paulo Freire. In: VII CONGRESSO NACIONAL DE EDUCAÇÃO, EDUCERE, 2008, Curitiba. Anais... Curitiba: PUCPR, 2008, p. 1238-1249.

POSSER, J.; ALMEIDA, L.H.; MOLL, J. Educação Integral: Contexto Histórico na Educação Brasileira. Revista de Ciências Humanas - Educação. v. 17, n. 28, 2016.

PRODANOV, C.C.; FREITAS, E.C. Metodologia do Trabalho Científico: Métodos e Técnicas da Pesquisa e do Trabalho Acadêmico. $2^{\underline{a}}$ ed. Novo Hamburgo: Feevale, 2013.

PROFICE, C.C. Educação Ambiental: Dilemas e Desafios no Cenário Acadêmico Brasileiro. REDE - Revista Eletrônica do PRODEMA. Fortaleza, v. 10, n. 1, p. 22-37, 2016.

RODRIGUES, D.G.; ANDREOLI, V.M. Desafios e perspectivas das ações educativo-ambientais na educação infantil. Revista Brasileira de Educação Ambiental. São Paulo, v. 11, n. 4, p. 130-148, 2016.

ROSA, T.S.; MENDONÇA, M.B.; MONTEIRO, T.G.; SOUZA, R.M.; LUCENA, R. A Educação Ambiental como Estratégia para a Redução de Riscos Socioambientais. Ambiente \& Sociedade. v. XVIII, n. 3, p. 211-230, 2015.

SAMPIERI, R.H.; COLLADO, C.F.; BAPTISTA LUCIO, M.P. Metodologia de Pesquisa. 5aㅡ. ed. São Paulo: Penso Editora, 2013.

SANTOS, V.S.; SCHIMITT, J.L.; ROSA, M.D. A educação ambiental como potencial para o gerenciamento de resíduos sólidos escolares: O caso da EMEF Boa Saúde, Novo Hamburgo (RS). Revista Brasileira de Educação Ambiental. São Paulo, v. 11, n. 5, p. 53-66, 2016.

SAVIANI, D. Sistema Nacional de Educação articulado ao Plano Nacional de Educação. Revista Brasileira de Educação. v. 15, n. 44, 2010.

SIMSEKLI, Y. An Implementation to Raise Environmental Awareness of Elementary Education Students. Procedia: Social and Behavioral Science. v. 191, p. 222-226, 2015.

SMITH, D.G. Curriculum and Teaching Facing Globalization. In: PINAR, W. F. (Ed.). International Handbook of Curriculum Research. London: LEA Publishers, p. 35-52, 2003.

SOUZA, G.S.; MACHADO, P.B.; REIS, V.R.; SANTOS, A.S.; DIAS, V.B. Educação Ambiental como Ferramenta para o Manejo de Resíduos Sólidos no Cotidiano Escolar. Revista Brasileira de Educação Ambiental. Rio Grande, v. 8, n. 2, p. 118-130, 2013.

STEVENSON, R.B. Schooling and Environmental Education: Contradictions in Purpose and Practise. Environmental Education Research. v. 13, n. 2, p. 139-153, 2007. 
TITTON, M.B.P.; PACHECO, S.M. Diálogos possíveis à Construção de Projeto Político e Pedagógico na perspectiva contemporânea da Educação Integral. Educação em Revista. Belo Horizonte, v. 31, n. 04, p. 135-153, 2015.

TORNQUIST, A.; BECKER, C.; SIMMIANER, J.; PREUSS, L. Projeto materiais recicláveis: Um relato de prática em educação ambiental. Revista Brasileira de Educação Ambiental. Rio Grande, v. 8, n. 2, p. 164-168, 2013.

UNESCO. Educação 2030: Declaração de Incheon e Marco de Ação da Educação, Rumo a uma Educação de Qualidade Inclusiva e Equitativa e à Educação ao Longo da Vida para Todos. Brasília, 2016. 36 p.

VEIGA, A.A.A.; LUCAS, F.C.A.; PEREIRA, A.S.S.; SATO, K.S.S.; GERMANO, C.M. Diferentes Olhares e Ações para a Educação Ambiental: Um Exercício de Cidadania num Projeto de Extensão. Revista Brasileira de Educação Ambiental. Rio Grande, v. 7, n. 2, p. 67-76, 2012.

VOLPE, R.J.; SULDO, S.M. Introduction to the Special Issue on Theoretical Frameworks in School Psychological Intervention Research: Interdisciplinary Perspectives and Future Directions. School Psychology Review. v. 43, n. 2, p. 115-118, 2014.

WALS, A.E.J.; BRODY, M.; DILLON, J.; STEVENSON, R.B. Convergence between science and environmental education. Science. Publicado por AAAS, v. 344, 2014. 